\title{
Fine-structured Morphology of a Silicon Steel Sheet after Laser Surface Alloying of Sb Powder
}

\author{
Darja Steiner Petrovič $1, *$ - Roman Šturm² \\ 1 Institute of Metals and Technology, Ljubljana, Slovenia \\ 2 University of Ljubljana, Faculty of Mechanical Engineering, Slovenia
}

\begin{abstract}
An experiment was designed to investigate the feasibility of surface modifying a fully processed, non-oriented, electrical steel sheet with antimony (Sb) using laser surface alloying (LSA). The post-exposure microstructural characterization of the modified steel sheet was performed using light microscopy (LM) and field-emission scanning electron microscopy (FE-SEM/EDS).

Microhardness measurements confirmed the differences in the microhardness profile along the depth direction as a result of the applied laser-alloying treatment. The additive nature of the laser treatment and the specific cooling conditions create unique solidification conditions that ensure not only a high microhardness of approximately $400 \mathrm{HV}_{0.1}$ of the modified layer, but also its fine-structured morphology. Keywords: antimony, laser surface alloying, non-oriented electrical steel
\end{abstract}

\section{INTRODUCTION}

Non-oriented electrical steel sheets are soft magnetic materials produced from silicon steels. The Worldsteel Committee on Economic Studies, Brussels reports that the world-wide production of electrical sheet and strip in 2011 was 11.25 million tons [1].

Silicon steels are fundamental to the economy of electrical appliances, and offer the best combination for transmitting and distributing electrical energy. The properties required of these steels are high permeability and induction, low magnetic losses, and low magnetostriction [2]. International and national standards (e.g., EN 10106:2009) [3] only specify the maximum loss, and often also the minimization of polarization/permeability. Steels with a high content of silicon as the main alloying element are brittle and exhibit poor workability. Therefore, researchers are replacing the practice of adding silicon with alternatives - one of them being the addition of antimony ( $\mathrm{Sb}$ ) [4] to [7]. The positive effect of an $\mathrm{Sb}$ addition to silicon steels is reflected in a greater remanent induction and a lower coercive force, which should lead to a smaller area for the demagnetization loop and so to smaller inductive energy losses for nonoriented electrical steel sheet [6] and [7].

At present only high-permeability grades with excellent magnetic properties can provide a higher added value for electrical steels. The magnetic behaviour of electrical steels depends critically on the microstructure and the texture. Accordingly, a special design of silicon steel, by adding surfaceactive elements (i.e., $\mathrm{Sb}$ ) is expected to give improved magnetization properties for these soft magnetic materials [4], [5] and [7].
According to Takashima et al. [8], an Sb addition to $1.85 \%$ Si non-oriented electrical steels, with $0.25 \%$ $\mathrm{Mn}$ and $0.3 \% \mathrm{Al}$, improved the magnetic properties due to an increase of the (100) and (110) texture components and a decrease of the (111) texture component. The initial annealing treatment promotes an increase in the grain size and, additionally, $\mathrm{Sb}$ segregation at the grain boundaries. After cold rolling, during final annealing, the $\mathrm{Sb}$ prevents the nucleation of recrystallization near the original grain boundaries and decreases the formation of (111) grains [6] and [7]. In order to improve the crystallographic texture of non-oriented electrical steels, the amount of Sb should be between $0.015 \%$ and $0.15 \%$. The effect of $\mathrm{Sb}$ on the crystallographic texture depends on the hot-band annealing temperature, and its effectiveness is reduced when hot-band annealing is not performed [4] and [9].

On the other hand, various laser melting procedures can be effectively used during the creation of functional parts [10] to [13]. In recent years a laser beam has been used for a wide range of applications in order to modify the microstructure and the properties of the steel. The role of laser technology intensively increased in surface engineering. The most important processes are as follows: laser heat treatment, laser remelting, laser cladding and laser alloying [14].

Laser surface alloying (LSA) has attracted considerable attention in recent years as an efficient method to improve the chemical and mechanical surface properties of engineering components. The improvement in these properties by the LSA technique is achieved by introducing alloying materials into the laser-melted component surface, typically in the form of powder. For laser surface alloying, adding pre-paste metal powder on the substrate surface is a 
common practice. Because of the desire to mix the coating powder with the substrate, a thin layer of prepaste coating of the order of $0.1 \mathrm{~mm}$ to less than 1 $\mathrm{mm}$ of powder on the substrate is normally applied. The particles introduced in the interaction zone tend to completely dissolve in the liquid phase, thereby modifying the chemical composition of the surface layer. After the laser melting of both the coating powder and the substrate, an alloyed layer with a thickness normally less than $1 \mathrm{~mm}$ is obtained. The unique advantages of the LSA technique for surface modification are now well recognised and include the possibility of localised treatment, refinement of the grain size because of rapid quench rates and the generation of metastable structures with novel properties that are not achievable with competing methods [15] to [17].

The objective of the present study is to combine these two possible approaches, i.e., laser alloying of a surface-active element. The feasibility of the modification of a fully processed silicon steel sheet by the laser surface alloying of Sb powder will be investigated and discussed.

\section{EXPERIMENTAL PROCEDURE}

\subsection{Selection of Electrical Steel and Alloying Powder}

The chemical composition of the non-oriented electrical steel (NOES) under investigation is given in Table 1 . The alloying material was antimony $(\mathrm{Sb})$ powder containing $0.012 \mathrm{wt} . \% \mathrm{C}$ and $0.019 \mathrm{wt} . \% \mathrm{~S}$. The dimensions of the non-oriented electrical steel specimens were $70 \times 20 \times 0.5 \mathrm{~mm}$.

Table 1. Chemical composition of non-oriented electrical steel (wt.\%)

\begin{tabular}{ccccccc}
$\mathrm{C}$ & $\mathrm{Si}$ & $\mathrm{Al}$ & $\mathrm{Mn}$ & $\mathrm{N}$ & $\mathrm{P}$ & $\mathrm{Fe}$ \\
\hline 0.004 & 2.1 & 0.9 & 0.2 & 0.004 & 0.01 & Balance \\
\hline
\end{tabular}

In Fig. 1 the size distribution of the Sb powder particles is presented.

\subsection{Selection of the Laser Remelting Conditions}

Laser alloying of the thin surface layer was performed with a Nd:YAG laser system OR-LASER with a laser source maximum power $P=80 \mathrm{~W}$. The following laser parameters were selected:

Laser source power $\quad P=40 \mathrm{~W}$

Max. pulse energy $\quad E=60 \mathrm{~J}$
Mode structure multimode-top hat

Energy input $\quad E_{i}=10.7 \mathrm{~J} / \mathrm{mm}^{2}$

Pulse duration $\quad t_{b}=8 \mathrm{~ms}$

Pulse frequency $\quad v=7 \mathrm{~Hz}$

\section{Laser beam}

Travel speed

$v_{b}=150 \mathrm{~mm} / \mathrm{min}$

\section{Beam diameter on}

The specimen surface $D_{b}=1.4 \mathrm{~mm}$

Beam overlapping $\quad 40 \%$ of $D_{b}$

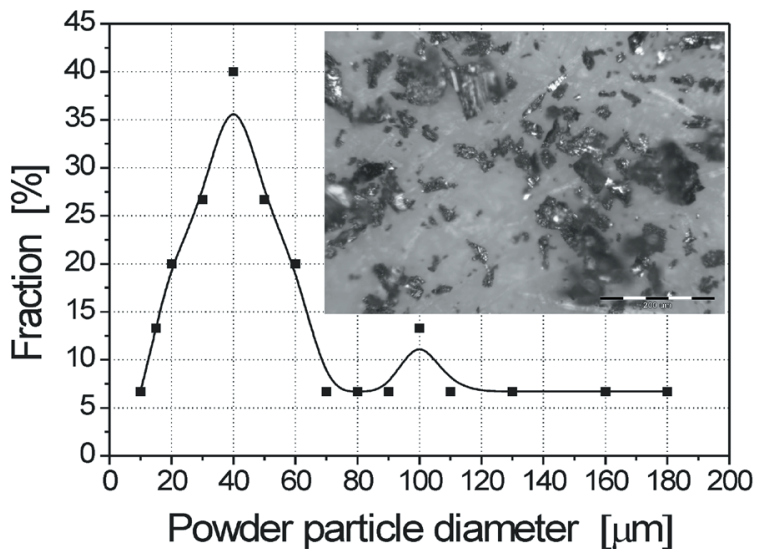

Fig. 1. Size distribution of Sb powder particles

A thin layer of pre-paste $\mathrm{Sb}$ coating (with an approximate thickness of $0.15 \mathrm{~mm}$ ) was applied to the substrate surface. For better adhesion of the $\mathrm{Sb}$ to the substrate surface, the $\mathrm{Sb}$ powder was mixed with alcohol to form a sort of wet paste. To avoid blowing away the $\mathrm{Sb}$ powder during the protective $\mathrm{Ar}$ gas flow, the experiment was performed in a regular air atmosphere. For this reason and the fact that the surface of fully processed electrical steel sheets is oxidized, a stationary air atmosphere seems to be more relevant for achieving the primary aim of the study.

The particles introduced in the interaction zone were expected to completely dissolve in the liquid phase, thereby modifying the chemical composition of the surface and subsurface layer.

However, the physical properties of the main elements of the electrical steel, i.e., $\mathrm{Fe}, \mathrm{Si}$, and $\mathrm{Al}$, and that of the $\mathrm{Sb}$ powder shown in Table 2 are very different. In particular, the $\mathrm{Sb}$ element volatilizes dramatically when melted due to its low melting point. Therefore, it is difficult to prepare Sb-type thermoelectric materials with a stoichiometric ratio. For the extensive application of Sb-type thermoelectric materials, it is necessary to develop optimal laser alloying parameters. 
Table 2. The physical properties of the main chemical elements involved in the laser alloying process

\begin{tabular}{lcccc} 
& $\mathrm{Sb}$ & $\mathrm{Fe}$ & $\mathrm{Si}$ & $\mathrm{Al}$ \\
\hline Melting point $\left[{ }^{\circ} \mathrm{C}\right]$ & 630.6 & 1535 & 1410 & 660.3 \\
\hline Boiling point $\left[{ }^{\circ} \mathrm{C}\right]$ & 1587 & 2750 & 2355 & 2467 \\
\hline Lattice type & $\begin{array}{c}\text { Simple } \\
\text { trigonal }\end{array}$ & b.c.c. & $\begin{array}{c}\text { Diamond } \\
\text { cubic }\end{array}$ & b.c.c. \\
\hline
\end{tabular}

\subsection{Metallographic Analysis}

For the metallographic analyses the sample was ground and polished according to standard metallographic techniques. The metallographic analyses were performed using a Microphot FXANikon light microscope and a JEOL JSM 6500-F field-emission scanning electron microscope with an associated energy-dispersive spectrometer (EDS). In this study, the FE-SEM/EDS analyses were performed at a $15-\mathrm{kV}$ accelerating voltage. In FESEM/EDS analyses the teardrop-shaped interaction volume extends from less than $100 \mathrm{~nm}$ to around 5 $\mu \mathrm{m}$ into the surface, depending on the element and the accelerating voltage. The factors that determine the detection limits of the EDS are the counting time, the accelerating voltage, the beam current, the line used to measure the element and the compositions of both the sample and the standards. The Vickers microhardness $\mathrm{HV}_{0.1}$ was measured using an Instron, Wilson-Wolpert Tukon 2100B hardness tester. The thermodynamic calculations were performed using ThermoCalcTCFE5. Additionally, a computer simulation of the solidification of the selected multi-component alloy was performed with the Scheil-Gulliver model. However, in the Scheil-Gulliver model no kinetic description of the solidification is given [18].

\section{RESULTS AND DISCUSSION}

\subsection{Dimensions of the Surface-Alloyed Layer}

When applying laser surface alloying it is important to ensure sufficient energy input so that melting of the thin surface layer is guaranteed. The size of the alloyed layer was defined in the cross-section of the specimen. For metallographic analysis, the specimen was cut in the transverse direction, ground, polished and etched for observation with a light microscope. The depth of the alloyed trace was then measured. The depth of the surface-alloyed layer was approximately $0.1 \mathrm{~mm}$.

\subsection{Microstructure Analysis of the Surface-Alloyed Layer}

In this study a commercial, fully processed specimen of non-oriented, electrical steel sheet of thickness 0.5 $\mathrm{mm}$ was used. Its oxide scale and the microstructure are represented in Figs. 2a and b, respectively. For the purposes of a standard metallographic investigation three lamellae were embedded (Fig. 2b).

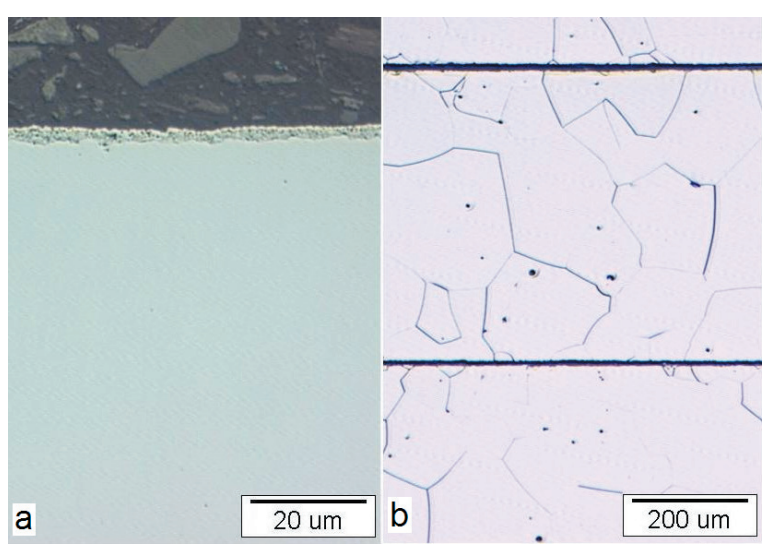

Fig. 2. Oxide scale, and the microstructure of the fully processed, non-oriented electrical steel sheet: a) non-etched, LM, 500× and b) etched by Nital, LM, 50x

The oxidized surface of non-oriented electrical steels is a consequence of the fabrication route, which includes final annealings for decarburization and recrystallization (Figs. 2a and b). The oxide scale of non-oriented electrical steel sheet formed in an industrial process is composed of iron oxide(s), silica, alumina and other complex oxides. The scale is normally several micrometres thick, with up to a micrometre of surface corrugation (Fig. 2a). Since the surface of fully processed, non-oriented electrical steel sheets is already oxidized, this may be an additional source of possible oxidation during the laser surface alloying [19]. Due to the high silicon content, the microstructure of the selected alloy consists of $\alpha$-ferrite, i.e., the b.c.c. phase (Fig. 2b).

For the prediction of the solidification process of the Fe-Si-Al alloy a modified Scheil-Gulliver solidification model can be used. This model assumes that the diffusion coefficients in the liquid phase are equal to infinity, whereas in the solid phases they are equal to zero, and that the local equilibrium is always held at the interphase between the liquid and solid phases. The modified Scheil-Gulliver model also allows equilibrium back diffusion of interstitial elements in solid phases [18].

The plotted diagram in Fig. 3.a shows how the mole fraction of the individual solid phases varies 
with temperature. Assuming the full-equilibrium calculation model, the calculated liquidus and solidus temperatures are 1512 and $1489{ }^{\circ} \mathrm{C}$, respectively (black dashed curve). In the simulation using the modified Scheil-Gulliver model the back-diffusion of fast-diffusing components (i.e., carbon) and a possible $\alpha \rightarrow \gamma$ transformation are taken into account. Here, the calculated liquidus temperature is $1371^{\circ} \mathrm{C}$. Compared to full-equilibrium conditions, the solidification sequence in this case proceeds with the precipitation of $\alpha$-ferrite over a much broader temperature interval.
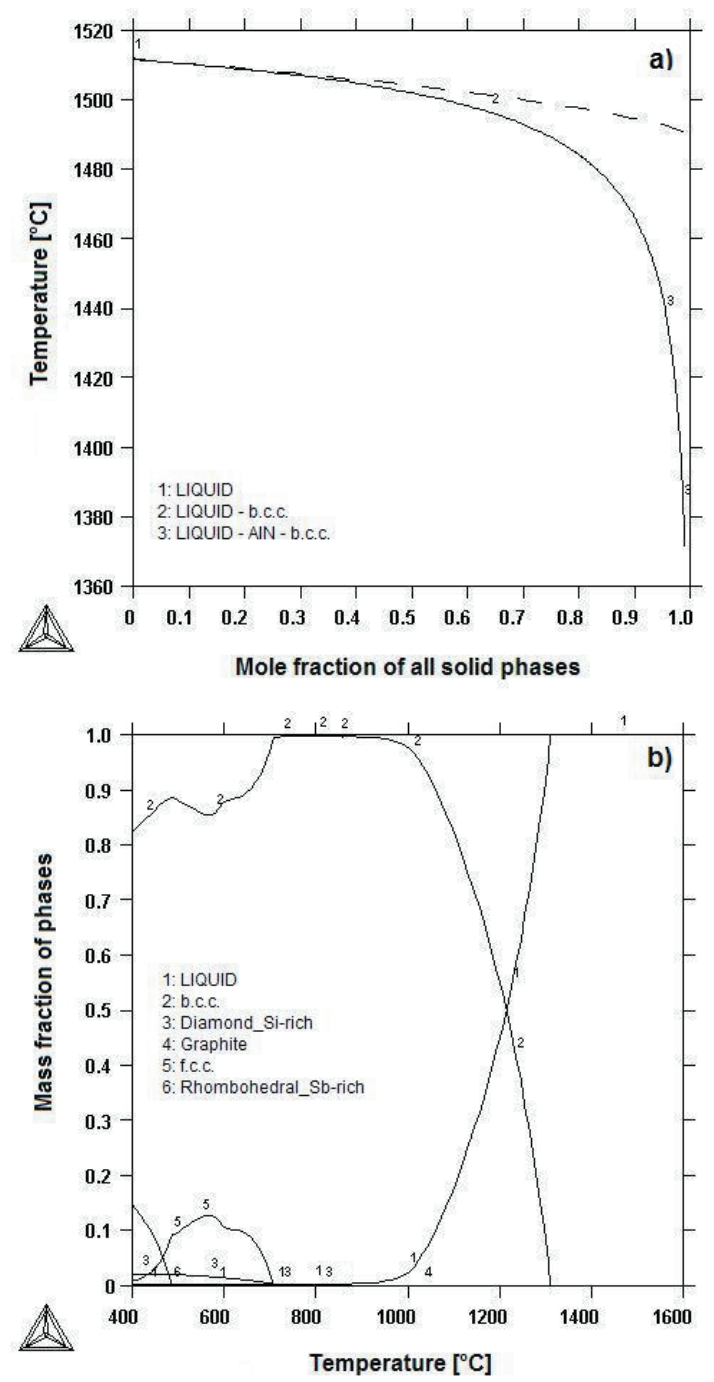

Fig. 3. a) Mole fractions of individual solid phases as a function of temperature (black curve for modified Scheil-Gulliver calculation and black dashed curve for full-equilibrium calculation); b) mass fraction of equilibrium phases as a function of temperature for the selected Fe-Si-Al alloy with Sb addition
The calculated values from Fig. 3a can be valuable for the prediction of the liquidus temperature. In the process of laser surface remelting, full-equilibrium conditions of the solidification cannot be achieved. Instead, due to the significantly higher solidification rates present the formation of hardening structures occurs. In Fig. $3 b$ the calculated phase equilibria (mass fraction of stable phases) in the temperature range 400 to $1600{ }^{\circ} \mathrm{C}$ are shown. Because of the limited solubility of $\mathrm{Sb}$ in $\alpha$-ferrite at room temperature, $\mathrm{Sb}$ rich precipitates (rhombohedral phase) are formed, whereas approximately $0.03 \mathrm{wt} . \% \mathrm{Sb}$ is dissolved in the ferrite.

The post-exposure metallographic analysis revealed the modified subsurface region in the ferritic steel sheet (Fig. 4). There is also evidence for a high cracking susceptibility of the alloyed layer.

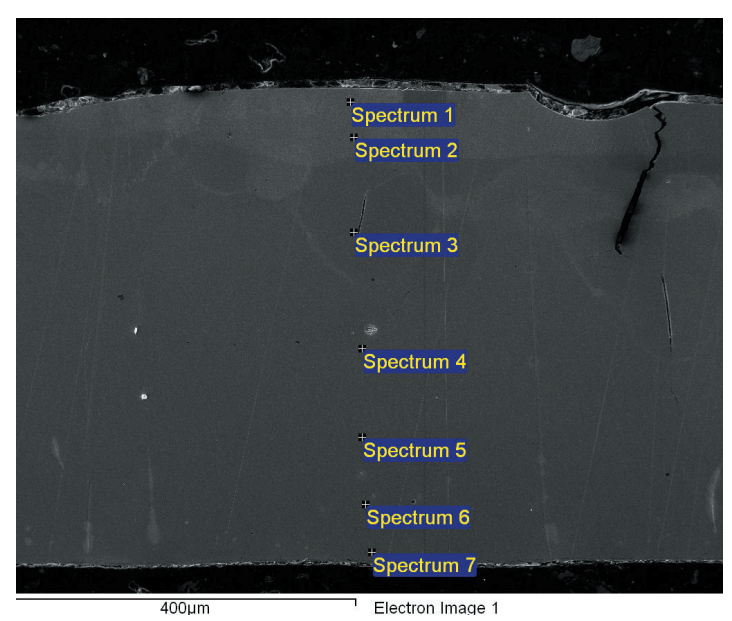

Fig. 4. SE image of the cross-section of the Sb-modified nonoriented electrical steel sheet using laser alloying

The distribution of $\mathrm{Sb}$ along the penetration depth direction of the laser-treated silicon steel can be seen from the corresponding EDS analyses (Fig. 5, Table $3)$.

The $\mathrm{Sb}$ enrichments were measured in spectra 1 and 2. The approximate penetration depth of the $\mathrm{Sb}$ was $0.1 \mathrm{~mm}$, which corresponds to the dimensions of the remelted layer.

Across the melt pool the as-solidified microstructure is present (Fig. 6a). The reaction front of the solidification can be seen at an approximate depth of $0.1 \mathrm{~mm}$. Moreover, the solidification conditions cause a very fine-structured morphological texture in the melt pool (Figs. 6a and b). From a comparison of Figs. $2 b$ and $6 a$ and $b$, these differences in the size and morphology of the bulk and surfacetreated material can be clearly seen. 


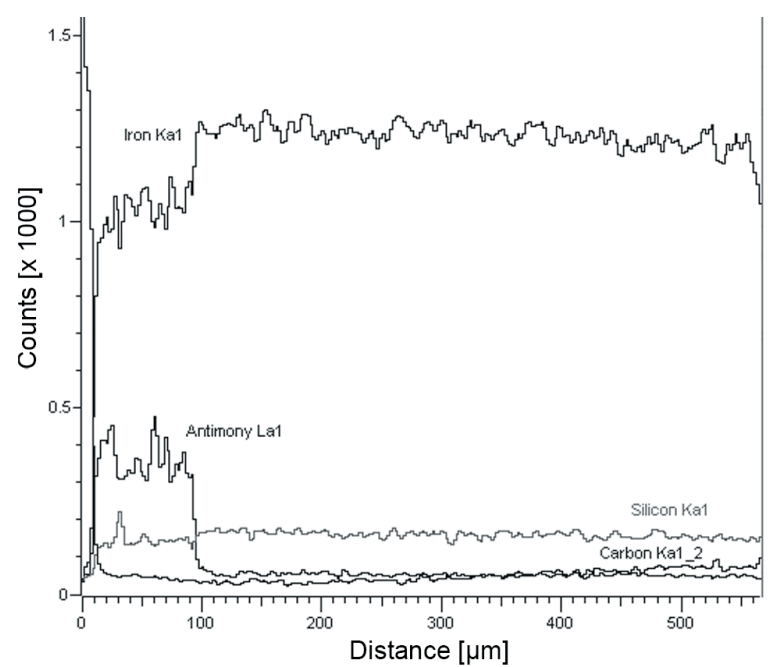

Fig. 5. Distribution of the elements $\mathrm{Sb}, \mathrm{Fe}, \mathrm{Si}$, and $\mathrm{C}$ along the penetration depth direction of the laser-treated silicon steel

(X-ray linescan)

Table 3. EDS analysis from Fig. 4 (results are given in wt.\%)

\begin{tabular}{lccccc}
\hline & C $^{*}$ & $\mathrm{Al}$ & $\mathrm{Si}$ & $\mathrm{Fe}$ & $\mathrm{Sb}$ \\
\hline Spectrum 1 & 5.84 & $/$ & 0.94 & 66.85 & 26.36 \\
\hline Spectrum 2 & 4.90 & $/$ & 1.15 & 65.92 & 28.02 \\
\hline Spectrum 3 & 3.99 & $/$ & 2.16 & 93.85 & $/$ \\
\hline Spectrum 4 & 2.44 & 0.76 & 2.16 & 94.64 & $/$ \\
\hline Spectrum 5 & 5.24 & 0.82 & 2.18 & 91.76 & $/$ \\
\hline Spectrum 6 & 7.56 & 0.91 & 1.87 & 89.66 & $/$ \\
\hline Spectrum 7 & 9.15 & 0.83 & 2.05 & 87.98 & $/$ \\
\hline
\end{tabular}

*Cummulative value of adsorbed and bulk carbon content.

The high cooling rates of the homogeneous melt give us the important effect of the formation of a fine dendrite microstructure. Thus, the formation of a very fine and homogeneous microstructure of the solution crystals of iron-silicon-antimony alloy system can be explained by the thermo-kinetic processes caused by the rapid cooling rates (Fig. 4).

In the investigated microstructure, some solidification cracks and pores are also visible (Fig. $6 \mathrm{~b})$. The cracks occur most probably due to the synergistic effects of high contents of Si and $\mathrm{Sb}$ in the remelted layer.

In the literature, crack- and pore-free coatings on low silicon steel (1 wt.\% Si) based on $\mathrm{Fe}_{3} \mathrm{Si}$ have already been reported [20].

\subsection{Microhardness in the Remelted Layer}

The microhardness was measured in accordance with the Vickers method, i.e., a diamond pyramid hardness measurement, through the depth of the alloyed layer. The hardness was measured at a load of 100 N. Fig. 7 shows the microhardness values through the alloyed layer. From the results shown in Fig. 7 it can be concluded that:

- After laser alloying of the Sb powder to the surface layer of non-oriented electrical steel an average microhardness level of around 410 to $420 \mathrm{HV}_{0.1}$ was obtained.

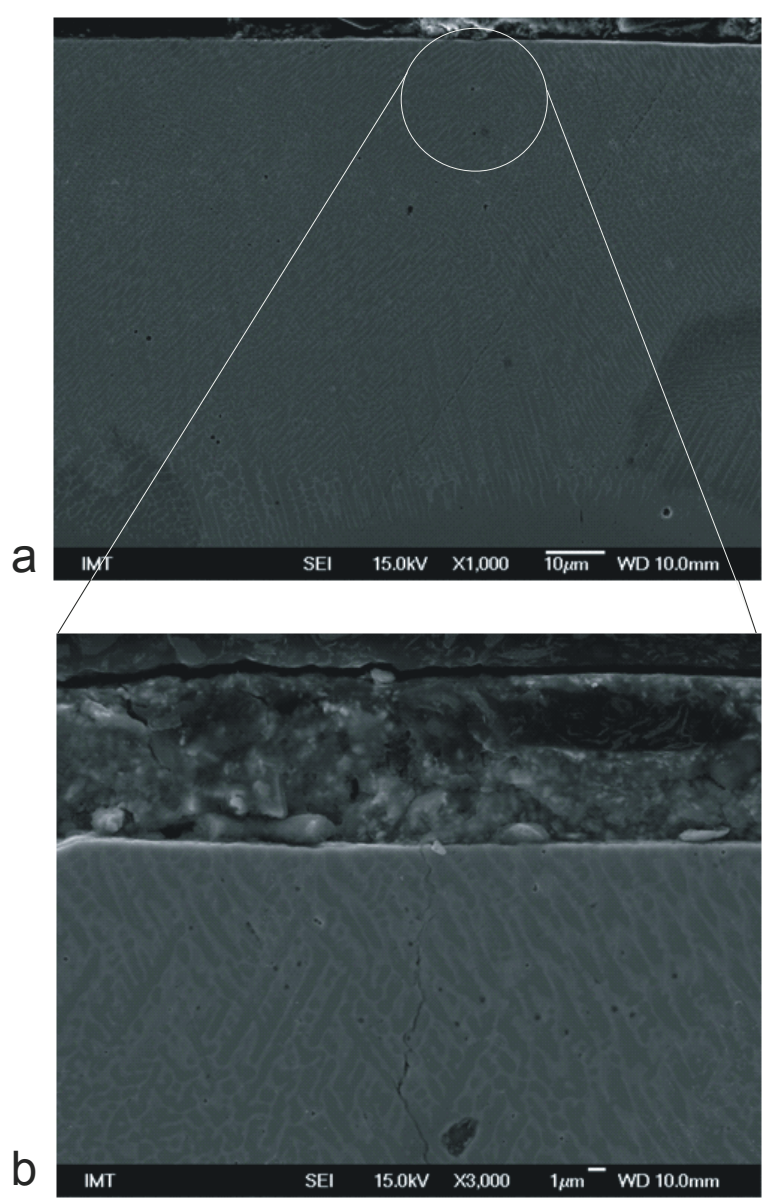

Fig. 6. a) As-solidified microstructure across the melt pool; b) finestructured morphology in the sub-surface region of the modified layer; cracks and pores are also visible

- There is a significant decrease in the microhardness in the transition zone from the alloyed layer to the base metal.

- The microhardness of the silicon steel substrate is $200 \pm 5 \mathrm{HV}_{0.1}$.

The comparison of the results of the metallographic analyses and the microhardness measurements shows a very good agreement. The results of the microhardness measurements correspond to the morphological changes in the surface alloyed layer (Figs. 4 and 7). 


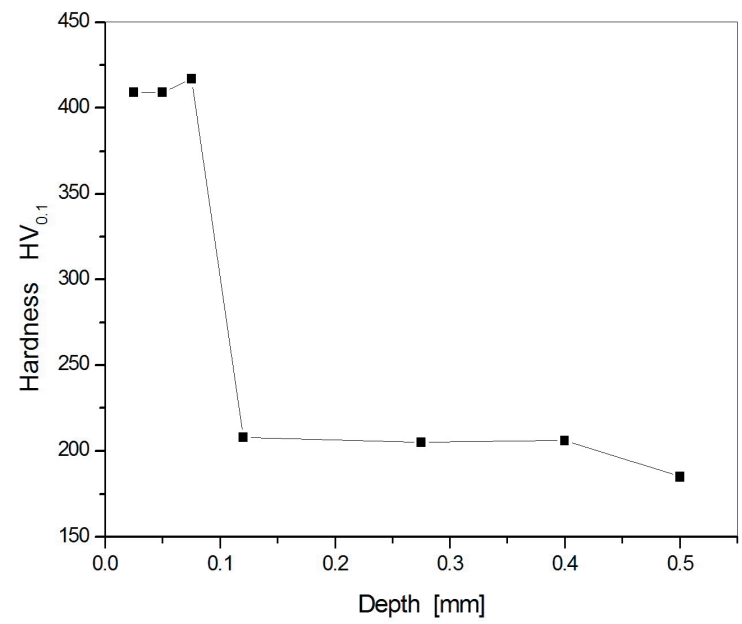

Fig. 7. Microhardness profile along the penetration depth direction of the laser-treated silicon steel sheet

In the process of laser surface remelting, the full-equilibrium conditions of the solidification cannot be achieved. Instead, due to the very high cooling rates a fine-structured dendrite morphology with an increased microhardness evolved. Using laser treatment the alloying with $\mathrm{Sb}$ is limited only to the region of the melt pool. As evident from Fig. 5, no further diffusion of $\mathrm{Sb}$ into the steel matrix occurs.

\section{CONCLUSIONS}

An experiment was designed to investigate the modification of a fully processed, non-oriented electrical steel sheet with antimony using laser surface alloying.

The applied laser treatment is appropriate for the modification of silicon steel sheet with $\mathrm{Sb}$. The following findings confirm the feasibility of the laser surface alloying of $\mathrm{Sb}$ powder in non-oriented electrical steel:

- With the applied parameters the approximate penetration depth of $\mathrm{Sb}$ by laser alloying was 0.1 $\mathrm{mm}$.

- The additive nature of the process and the specific cooling conditions create unique solidification conditions that ensure a fine-structured morphology.

- Process of laser surface alloying caused an increase in the hardness in the alloyed surface layer.

This preliminary study represents a novel approach to the tailoring of the commodity (i.e., electrical steel). A limitation here is the very high cracking susceptibility of the alloyed layer which can be minimized by the optimization of the applied process parameters. Nevertheless, the specifics of the selected surface modification that ensure a finestructured morphology may consequently have a beneficial effect on the further development of new soft magnetic materials produced from silicon steels.

\section{ACKNOWLEDGEMENTS}

The authors would like to acknowledge the Slovenian Research Agency for its financial support (Programmes P2-0050 and P2-0270).

\section{REFERENCES}

[1] Steel Statistical Yearbook (2012). Worldsteel Committee on Economic Studies, Brussels.

[2] Cullity, B.D., Graham, C.D. (2009). Introduction to Magnetic Materials. John Wiley \& Sons, Hoboken.

[3] SIST EN 10106:2007. Cold rolled non-oriented electrical steel sheet and strip delivered in the fully processed state, Slovenian Institute for Standardization, Ljubljana.

[4] Rodrigues, M.F., Da Cunha, M.A., Paolinelli, S.D.C., Cota, A.B. (2013). Texture and magnetic properties improvement of a $3 \% \mathrm{Si}$ non-oriented electrical steel by $\mathrm{Sb}$ addition. Journal of Magnetism and Magnetic Materials, vol. 331, p. 24-27, DOI:10.1016/j. jmmm.2012.11.009.

[5] Huang, W.Y., Chang, S.K., Zhou, S.C. (2006). The effect of alloys on the magnetic properties of high grade non-oriented electrical steels. Proceedings of the 9th International Steel Rolling Conference and $4^{\text {th }}$ European Conference. Paris.

[6] Jenko, M., Vodopivec, F., Praček, B. (1992). AES studies of antimony segregation on the surface of a Fe-Si-C alloy. Vacuum, vol. 43, no. 5-7, p. 449-451, DOI:10.1016/0042-207X(92)90054-Z.

[7] Jenko, M., Vodopivec, F., Praček, B., Godec, M., Steiner, D. (1994). AES studies of antimony surface segregation in nonoriented silicon steel. Journal of Magnetism and Magnetic Materials, vol. 133, no. 1-3, p. 229-232. DOI:10.1016/0304-8853(94)90533-9.

[8] Takashima, M., Obara, T., Kan,T. (1993). Texture improvement in high-permeability non-oriented electrical steel by antimony addition. Journal of Materials Engineering and Performance, vol. 2, no. 2, p. 249-254, DOI:10.1007/BF02660293.

[9] Irie, T.C., Matsumura, K.I., Nakamura, H.C., Shimanaka, H.F., Suzuki, T.C. (1980). Method of Producing Non-Oriented Silicon Steel Sheets Having an Excellent Electro-magnetic Property. United States Patent, Alexandria.

[10] Šturm, R., Grum, J. (2011). The influence of retained austenite on residual stresses in laser remelted cast iron. Journal of Materials Engineering and Performance, 
vol. 20, no. 9, p. 1671-1677, DOI:10.1007/s11665-0119833-3.

[11] Thijs, L., Kempen, K., Kruth, J.P., Van Humbeeck, J. (2013). Fine-structured aluminium products with controllable texture by selective laser melting of prealloyed AlSi10Mg powder. Acta Materialia, vol. 61, no. 5, p. 1809-1819, DOI:10.1016/j.actamat.2012.11.052.

[12] Ravnikar, D., Mrvar, P., Medved, J., Grum, J. (2013). Microstructural analysis of laser coated ceramic components TiB2 and TiC on aluminium alloy EN AW6082-T651. Strojniški vestnik - Journal of mechanical Engineering, vol. 59, no. 5, p. 281-290, DOI:10.5545/ sv-jme.2012.904.

[13] Sušnik, J., Šturm, R., Grum, J. (2012). Influence of laser surface remelting on Al-Si alloy properties. Strojniški vestnik - Journal of Mechanical Engineering, vol. 58, no. 10 , p. 614-620, DOI:10.5545/sv-jme.2012.696.

[14] Major, B. (2006). Laser processing for surface modification by remelting and alloying of metallic systems. Pauleau, Y., (ed.). Materials Surface Processing by Directed Energy Techniques. Elsevier, Amsterdam, p. 241-274.

[15] Dobrzanski, L.A., Bonek, M., Hajduczek, E., Klimpel, A. (2005). Alloying the X40CrMoV5-1 steel surface layer with tungsten carbide by the use of a high power diode laser. Applied Surface Science, vol. 247, no 1-4, p. 328-332, DOI:10.1016/j.apsusc.2005.01.126.
[16] Nath, S., Pityana, S., Majumdar, J.D. (2012). Laser surface alloying of aluminium with $\mathrm{WC}+\mathrm{Co}+\mathrm{NiCr}$ for improved wear resistance. Surface \& Coatings Technology, vol. 206, no. 15, p. 3333-3341, DOI:10.1016/j.surfcoat.2012.01.038.

[17] Sun, G., Zhang, Y., Liu, C., Luo, K., Tao, X., Li, P. (2010). Microstructure and wear resistance enhancement of cast steel rolls by laser surface alloying NiCr-Cr3C2. Materials and Design, vol. 31, no. 6, p. 2737-2744, DOI:10.1016/j.matdes.2010.01.021.

[18] Andersson, J.O., Helander, T., Höglund, L., Shi, P., Sundman, B. (2002). Thermo-Calc \& DICTRA, computational tools for materials science. Calphad, vol. 26, no. 2, p. 273-312, DOI:10.1016/S03645916(02)00037-8.

[19] Steiner Petrovič, D., Mandrino, Dj. (2011). XPS Characterization of the oxide scale on fully processed non-oriented electrical steel sheet. Materials Characterization, vol. 62, no 3, p. 503-508, DOI:10.1016/j.matchar.2011.03.011.

[20] Dong, D., Liu, C., Chen, S., Zhang, B. (2009). Characterization of Fe3Si-based coatings on low silicon steel by pulsed Nd:YAG laser cladding. International Journal of Minerals, Metallurgy and Materials, vol. 16, no. 2, p. 208-214, DOI:10.1016/S1674-4799(09)600352. 